and loosens or 'opens up' again in the spring : confirm. ation of this observation-important in quantitative studies on fish and fish food-offers a difficult problem for the biologist. The Flookborough sands appear 'harder' in winter, but this may be due to lack of drought and drainage, factors which would not, however, operate below sea-level. Whether the fisherman's hardening of the sea-bottom might be due to biological phenomena, such as a relative quiescence of the in-fauna, or to physical causes, remains to be sought.

University of Liverpool.

J. H. Orton. May 11.

\section{Strange Sounds from Inland Ice, Greenland}

During the month of August 1932, when setting up the French Expedition of the International Polar Year in Scoresby Sound, on the East Greenland coast, some of my colleagues and I heard four times the mysterious sound called by the late Prof. A. Wegener the "Ton der Dove-Bai"'. The sound was heard in the morning, generally at 11 a.m. (G.M.T.), and also during the afternoon. It was a powerful and deep musical note coming far from the south, lasting a few seconds. It resembled the roaring of a fog-horn. After that it was not heard during the course of the Polar Year.

A. Wegener and five of his companions heard it eight times in five different neighbouring places, both during the day and the polar night. It lasted sometimes a few minutes and Wegener ascribed it to the movements of inland ice. In fact, it seemed, in Scoresby Sound, to come from beyond Cape Brewster, precisely from the part of the coast where the inland ice flows into the sea from the large glaciers.

Is this vibrating sound really caused by the detachment of icebergs or is it similar to the 'desert song', that strange musical note produced by the sand? In fact, there is a close analogy between the fields of powdery dry snow of the inland ice and the fields of sand of the Arabian desert.

12 rue Lord Byron,

A. Dauvillimer.

$$
\text { Paris, } 8 .
$$

1 J. P. Koch und A. Wegener : Meddelelser om Grønland, Bd. 75, 314 ; 1930 (Dove Bay: $76 \frac{1}{4}^{\circ} \mathrm{N}$., $20^{\circ}$ W.).

\section{Spearman's General Factor without the Indeterminate Part}

IT is well-known that Spearman's two-factor theory of intelligence leads to an expression for the general factor $g$ containing an indeterminate part ${ }^{1}$. Considerable discussion has taken place on the inconvenience so caused. I have proved that if we adhere strictly to the conditions laid down by Spearman, namely, that the general factor and the specific factors are all mutually uncorrelated, we cannot dispense with the indeterminate part ${ }^{2}$.

However, the problem can be stated in another way, which seems likely to prove much more convenient in practice. Let us define the approximate general factor $g^{\mathbf{1}}$ as the determinate part of the formula obtained for $g$ (with a slightly different multiplier so as to keep the standard deviation unity), with a similar definition for the approximate specific factors. Then I have proved that these approximate specific factors are all approximately uncorrelated with each other and exactly uncorrelated with the approximate general factor. For Brown and Stephenson's results no coefficient of correlation of these approximate specific factors is numerically greater than about $0 \cdot 1$.

A detailed proof will be offered for publication elsewhere.

University College, Nottingham. April 25.

1 Brit. J. Prychol., 24, 88 ; 1933.

Lecture to Manchester Mathematical Society, Feb. 14, 1934 (unpublished).

\section{The Reaction between Oxygen and the Heavier Isotope of Hydrogen}

WE have made a preliminary survey of the principal respects in which the reaction of deuterium with oxygen differs from that of ordinary hydrogen. The deuterium was prepared by the nearly quantitative decomposition of 97 per cent deuterium oxide by repeated passage over pure iron. The reaction with oxygen was studied by methods which have been used in this laboratory in a number of previous investigations of the normal hydrogen-oxygen reaction. All experiments with deuterium were made in alternation with blank experiments earried out sometimes with cylinder hydrogen and sometimes with hydrogen made from water in the apparatus used for preparing the deuterium. No differences between these different specimens of normal hydrogen were found.

The results may be summarised as follows :-

(a) With deuterium the chain reaction occurring in the gas phase at $560^{\circ}$ and pressures greater than the upper explosion limit has a speed 64 per cent of that shown by hydrogen.

(b) For the surface reaction occurring in a packed vessel at $525^{\circ}$, the ratio of the rates for deuterium and for hydrogen is approximately $0 \cdot 65-0 \cdot 70$.

(c) The upper explosion limit is higher with deuterium than with hydrogen. Our results here correspond to those of Frost and Alyea ${ }^{1}$, which appeared during the course of the present work. The shifting of the limit is almost exactly what would be predicted from the theory of deactivation by ternary collisions. Deuterium, on account of its smaller speed, is a less efficient deactivating agent. Using the formulæ given by Grant and Hinshelwood ${ }^{2}$, we find that to account for the observed shift of the limit at $550^{\circ}, 525^{\circ}$ and $500^{\circ}$ respectively, the values required for the relative collision frequencies of deuterium and hydrogen are $0.67,0.76$ and 0.76 , the mean being $0 \cdot 73$. The value calculated from the respective molecular weights, assuming equal collision areas, is $0 \cdot 74$. This is, indeed, a good confirmation of the ternary collision hypothesis itself.

For the energy of activation of the branching process we find 26,500 calories, which does not differ significantly from the values 25,500 and 26,500 found for hydrogen.

From the fact that the effect of the deuterium can be calculated from its speed as above, we must conclude that there is little difference in the actual probability of chain branching with the two isotopes. If, as has been suggested ${ }^{3}$, the branching depends upon whether at a certain stage of the chain $\mathrm{H}_{2}+\mathrm{HO}_{2}$ gives $\mathrm{H}+\mathrm{H}_{2} \mathrm{O}_{2}$ or $\mathrm{H}+2 \mathrm{OH}$, it will be determined by the breakdown of $\mathrm{H}-\mathrm{O}-\mathrm{O}-\mathrm{H}$ into $2 \mathrm{OH}$. Then, 